\title{
Empirical Analysis on the Influential Factors of Real Estate Price: A Panel VAR Model View
}

\author{
Yang Lu \\ School of Economics \\ Jiangxi University of Finance and Economics \\ Nanchang, China
}

\begin{abstract}
The cities in China have had a period of great prosperity and rapid economic growth due to marketization of housing policy since 1998. This paper empirically compares the relationship between economic fundamentals and non-economic fundamentals and real estate prices by establishing a panel data VAR model from 2005 to 2015 . This paper adopts the data of real estate prices, economic factors, and non-economic factors in $\mathbf{3 1}$ provinces and cities, and the panel VAR model to examine the explanatory power of relevant influencing factors by the panel VAR model impacted on the house prices. The results indicate that the economic factors significantly have impact on rising real estate prices while the non-economic factors do not significantly have impact on rising real estate prices. This research concludes that if the change in real estate prices declines, the real estate prices, land supply, income and real estate development loans will increase. Yet the inflation rate will go up if the change in real estate prices rises. The contribution of this study provides some policy suggestions on the situation of the Chinese real estate market.
\end{abstract}

Keywords-Real Estate Prices; Panel VAR Model (PVAR); Economic Factors; Non-economic Factors

\section{INTRODUCTION}

The cities in China have had a period of great prosperity and rapid economic growth due to marketization of housing policy since 1998. Owing to the influx of rural population, urban population have been increasing and further promoted the rapid development of the real estate industry in China. As a result, the real estate industry in China gradually evolved into the national pillar industry. In 2000, China began to have certain norms in the real estate market. The "land reform" in 2002 was publicly traded adopting the land agreement transfer method. The Measures for the Administration of Affordable Housing were officially implemented in 2004.

In recent years, China regulated the real estate market and even stimulated consumption and prosperity of the real estate market. After 2004, real estate prices rose rapidly and the government began to curb the rise in real estate prices. From "State 8" in 2005 to "New State 5" in 2013, most of the controlling policies are measures to curb real estate prices. During this period, the real estate market was briefly suppressed during the financial crisis of 2008, and the government introduced some policies at this time to make the real estate market develop steadily. After 2009, the real estate market quickly out of the downturn brought by the financial crisis, housing prices rebounded rapidly. Then, China began to implement "restriction order", and as a basic means of regulation of the real estate market. At the 19th Communist Party of China (CPC) National Congress in 2017, General Secretary Xi Jinping also responded to the housing policy and put forward the principle of "insisting that the house should be used for housing rather than for speculation and speeding up the establishment of multi-agent supply, Multi-channel protection, rent and purchase of both housing system, so that all people live in.".

The rapid development of Chinese real estate has made a contribution to its economic growth in recent years. Because of the unscientific management and policy implementation, the speculation of real estate developers and consumers makes the real estate prices rising unreasonably. From the Panel VAR data, the national average real estate sales price rose extremely from 15,200 per square meters in 2005 to 22,630 per square meter in 2015. However, with such a rapid rise, many problems to be solved have emerged in the development of the Chinese real estate market in the recent 20 years.

First, the real estate market supply is greater than its market demand. And because of the difference of urban and rural development in China, the demand for housing in urban and rural areas has always been very different, which further leads to the unbalance of supply and demand in Chinese real estate market. Second, the inventory of the Chinese real estate market is still too high. After the "supply-side reform" was started, the "de-stocking" in the first-tier cities had achieved good results. However, in the second and third-tier cities, the "de-stocking" policy did not achieve very good results. In general, the high inventory situation has been improved, but it is still a major problem in the Chinese real estate market. Although the government defines the scope of the revenue to purchase the affordable houses, there are a lot of affordable houses for sale and existing rent-seeking behavior due to unscientific supervision and some real estate developers' profit intention. So that some affordable housing has been turned into an investing housing.

In recent years, the rapid development of real estate made great contribution to the Chinese economy. Because of the unscientific management and no specific policy implementation, the speculation of real estate developers, buyers, and other factors make the real estate prices rise unreasonably. With such a rapid rising, although the Chinese real estate market has been developing in nearly 20 years, there have been many problems to be solved. 
First, there is a supply and demand imbalance problem in the real estate market. The supply of the real estate market is more than its market demand. And because of the difference of urban and rural development in China, there has always been a difference between the demand for housing in urban and rural areas, which further leads to the imbalance of supply and demand in Chinese real estate market. Second, the inventory in the real estate market is still too high. In general, the high inventory situation has been improved, but it is still a major problem in the Chinese real estate market. Finally, there is a protection of housing issues problem due to unscientific supervision and housing developers tend to unreasonable profit such as speculating affordable housing into an invest housing. Therefore, Chinese real estate markets need more scientific and effective control policies such as a macro-control policy to solve these problems.[6]

Real estate has always been one of the more important aspects of China, and there is a wide variation in provinces and municipalities. The purpose of this paper conducts research and analysis on the influential factors of real estate prices across the country to understand the impact of changes in real estate prices on economic factors and non-economic factors, based on the data of various provinces and cities in China from 2005 to 2015. The structure of this paper is as follows: the first part is the introduction about the Chinese real estate; the second part is the literature review; the third part is the theoretical model setting and results; the fourth part is the policy implication and conclusions.

\section{LITERATURE REVIEW}

Before the empirical analysis, it needs to analyze the impact of changes in real estate prices on the economy in China, and then study the influent factors of real estate prices on the real estate prices. Therefore, it can be more clearly and reasonably regulated a real estate price policy in China. After more than ten years of real estate market development, the real estate industry has become a pillar industry, which is closely related to Chinese economic development. However, the rapid rise of the real estate prices has also caused many problems on the Chinese economic development and has also brought unfavorable effects on the people's livelihood. Therefore, before studying the effect of influencing factors on real estate price, it is necessary to research these factors affecting real estate prices.

\section{A. The impact of Real Estate Price Changes on Real Estate Price}

The expected price of real estate is based on the historical price and growth rate of the real estate price. Therefore, the rise of the real estate price will cause people to have an expectation of rising. At the same time, investors also have a rise in the future real estate price expectations. As a herding effect in the real estate market, investors shall be able to earn the difference between the purchase of housing, which also makes the real estate prices prone to abnormal changes.[4]

\section{B. The Impact of Land Supply on Real Estate Prices}

Land resources in China have been under the control of the government, and the land resources are limited resources. In the short term, real estate prices can be restrained by increasing the supply of real estate. However, in the long run, the cost of land is also getting higher, which also leads to a faster rebound in real estate prices. Therefore, the supply of land on the real estate prices, the short term can curb real estate prices, but in the long-run real estate prices will rise.

\section{Inflation Rate Impacting on Real Estate Prices}

It is necessary to analyze different aspects of the impact of the inflation rate. On the one hand, the inflation rate will affect the rise of the price so that the price of construction materials will rise, thus affecting the construction cost and affecting the real estate price.[3] On the other hand, many investors regard houses as a commodity against inflation, which in turn adds to many real estate prices, which in any case have led to higher real estate prices.

\section{Impact of Real Estate Development Loan on Real Estate Price}

The more real estate development loans increase, the more real estate investors will promote the amount of real estate funds and lead to different effects of the real estate price. On the one hand, real estate investors in the short term do not need to sell houses as soon as possible, hoping to make more money, under the situation of the increase in the price of housing; on the other hand, the wealth of investors can also greatly increase the supply of real estate, which also makes real estate prices lower, but the impact of this takes time to be effective, Thus, real estate development loans in the short term can increase real estate prices; in the long-term, increase the supply of real estate reduce the price of its real estate.[8]

\section{E. The Impact of Income on Real Estate Prices}

Increased income will increase people's purchasing power, thereby increasing people's rigid demand for real estate prices, which is the main reason for real estate prices. Rapid economic development in China, people's income is also continuing to grow, which also makes Chinese real estate prices at a high level.[1]

\section{F. The Impact of Investment in Real Estate on Real Estate Prices}

On the one hand, the consumption of building materials is likely to be the result of an increase in construction prices, which will have an effect on the rise of real estate prices. On the other hand, the increase in investment in social housing projects will increase some real estate supply and has eased some rigid demand, which leads to a decline in real estate prices.[7] However, in some areas, the distribution of affordable housing is unscientific, resulting in some idleness, leading to an increase in real estate prices in the long run.

In general, the price of real estate will remain at a relatively high level for a long time due to the increase of income, and more factors will cause real estate prices to rise. Therefore, it is necessary to have a deeper understanding and analysis of these 
factors and thus avoid abnormal changes in real estate prices, reducing the adverse impact.

\section{The TheORETICAL Model SETting AND RESUltS}

\section{A. Model Variable Data Source and Processing}

Taking into account the economic factors and noneconomic factors and the relationship between real estate prices, some of the factors that are national, so this paper selects the provinces where the data can be analyzed. Therefore, this article chooses the price itself, the per capita income and the inflation rate in the economic fundamentals; selects the six factors of credit policy, land policy and social security policy in the non- economic factors to be analyzed.

In the economic factors, this article adopts the sales area of the province's real estate and sales amount of real estate to find out the average provinces' sales prices; per capita income selected in urban provinces is per capita disposable income; inflation rate selected is the province's Consumer Price Index (CPI) year-on-year growth rate. In the non-economic factors of the influencing factors, this article adopts the real estate investment loans representing the amount of real estate development loans; the land turnover in each province means the amount of land supply; the real estate investment in public welfare describes the protection of housing investment amount.

This paper adopts annual data from 31 provinces, autonomous regions and municipalities directly based on the Central Government from 2005 to 2015. In order to eliminate heteroscedasticity, the data in this paper are all logarithm, and the rate of data change of the logarithm is adopted for research and analysis.

TABLE I. STATISTICS DESCRIPTION

\begin{tabular}{|c|c|c|c|c|c|}
\hline Variable & $\begin{array}{c}\text { Data / } \\
\text { Number }\end{array}$ & Average & $\begin{array}{c}\text { Standard } \\
\text { Deviation }\end{array}$ & Minimum & $\begin{array}{c}\text { Maxi } \\
\text { mum }\end{array}$ \\
\hline $\mathrm{HP}^{1}$ & 341 & 0.4865765 & 0.3275414 & 0.1528675 & 2.263251 \\
\hline LAND $^{2}$ & 341 & 3110.123 & 2449.23 & 18.2538 & 11681.01 \\
\hline $\mathrm{CPI}$ & 341 & 2.903489 & 2.0119 & -2.3462 & 10.0865 \\
\hline $\mathrm{LOAN}^{3}$ & 341 & 1274.389 & 1034.097 & 4.6131 & 5382.218 \\
\hline $\mathrm{INC}^{4}$ & 341 & 19159.65 & 8210.695 & 7990.15 & 52962 \\
\hline $\mathrm{LAI}^{5}$ & 341 & 70.62584 & 71.10141 & 0.95 & 450.55 \\
\hline
\end{tabular}

Source: Statistical Yearbooks of Provinces and Guotai An Database.

From the above data, we can see the average, standard deviation, minimum and maximum of each variable. Based on these data, we can see that these factors in different regions have changed greatly in ten years, resulting in a dispersion of all data extremely.

\section{B. The Choice of Model}

Although the IV-GMM method can be used to reduce the endogeneity, the endogeneity cannot be completely eliminated. The panel VAR model, which has both the advantages of the panel data model and the time-series VAR model which can eliminate the endogeneity. Not only individual and time effects are considered, but also the impact of variable impact on other variables can be analyzed. Therefore, this paper adopts panel VAR (PVAR) model to study and analyze the relationship real estate prices between economic factors and non-economic factors and uses its impulse response to analyze the response of real estate prices in the face of impact. PVAR model and its Stata code firstly introduced by Love.[2] Stata12.0 software is also adopted to analyze the variables.

\section{EMPIRICAL ANALYSIS}

\section{A. Panel Unit Root Test}

In time series, the purpose of the unit root test is to avoid testing the un-stability of the time series for regression. Since the panel data includes both the characteristics of the crosssection data and the characteristics of the time series, the stability of the panel data needs to be checked to overcome the small-sample bias of a single time-series unit root test, thereby reducing to some extent unobservable individual effects and cross-sectional correlations. This article adopts the Levin-LinChu (LLC) test provided in the Stata software to perform a unit root test on panel data. The results are shown in the following table.

TABLE II. PANEL UNIT RoOT TEST RESUlts

\begin{tabular}{|c|c|c|c|}
\hline Variables & Test Statistic & P value & Conclusion \\
\hline HP & -4.4332 & 0.0000 & Stable \\
\hline LAND & -9.6414 & 0.0000 & Stable \\
\hline CPI & -3.7774 & 0.0000 & Stable \\
\hline LOAN & -6.8671 & 0.0000 & Stable \\
\hline INC & -10.0816 & 0.0000 & Stable \\
\hline IAI & -44.0903 & 0.0000 & Stable \\
\hline
\end{tabular}

Note: The results of Panel unit root test in the above table shows that the panel data are stable.

\section{B. Panel Lag Choice of VAR Model.}

Before the parameter estimation is performed, it is first necessary to select the lag order of the PVAR model. This paper adopts AIC, BIC, and HQIC information criteria to select the optimal lag order according to the minimum criteria in the guidelines. Hysteresis order selection results as follows:

TABLE III. The Results of PVAR MOdel LAG ORDER SELECTION

\begin{tabular}{|c|c|c|c|}
\hline Hysteresis & AIC Criterion & BIC Criterion & HQIC \\
\hline 1 & -3.29679 & 0.524962 & -1.74836 \\
\hline 2 & $-6.22918^{*}$ & $-0.730241^{*}$ & $-3.99455^{*}$ \\
\hline 3 & 35.4079 & 43.7983 & 38.7846 \\
\hline 4 & 60.0821 & 72.1261 & 64.7396 \\
\hline 5 & 132.642 & 147.483 & 138.146 \\
\hline
\end{tabular}

Note: The AIC criterion, BIC criterion and HQIC criterion choose lag two as the optimal choice.

\footnotetext{
1 the average provinces' sales prices

2 the amount of land supply

${ }^{3}$ the real estate investment loans

4 per capita disposable income

5 the real estate investment in public welfare
} 


\section{Graphical Analysis of Panel Impulse Response}

The paper studies the impact of influencing factors on real estate prices, which includes two aspects: firstly, the impact of economic factors on the equilibrium prices of real estate. Reflected in the model, namely, the equilibrium price of real estate, per capita disposable income of urban households and the impact of inflation on the equilibrium price of real estate; secondly, the impact of non-economic factors on the equilibrium price of real estate. Real estate development loans, land supply and the change of developing protection house investment impact on the equilibrium price of real estate. Therefore, the above two aspects are separately analyzed according to the impulse response diagram (IRF) in Stata software. The following impulse response plots show the lag order of the shock, due to the annual data, the lag first order represents one year, the vertical axis represents the response of the response variable, and the solid line represents a variable over time impulse response to standard deviation information of another variable, dashed line indicates the confidence band on both sides of the response pulse pattern or minus two standard deviations, due to the government's macroeconomic plan of 5 years, the following pulse patterns are all defined as 5 issues. The data at this time is taken as the logarithm, and the graph shows the effect of the change of the factor on the real estate price.

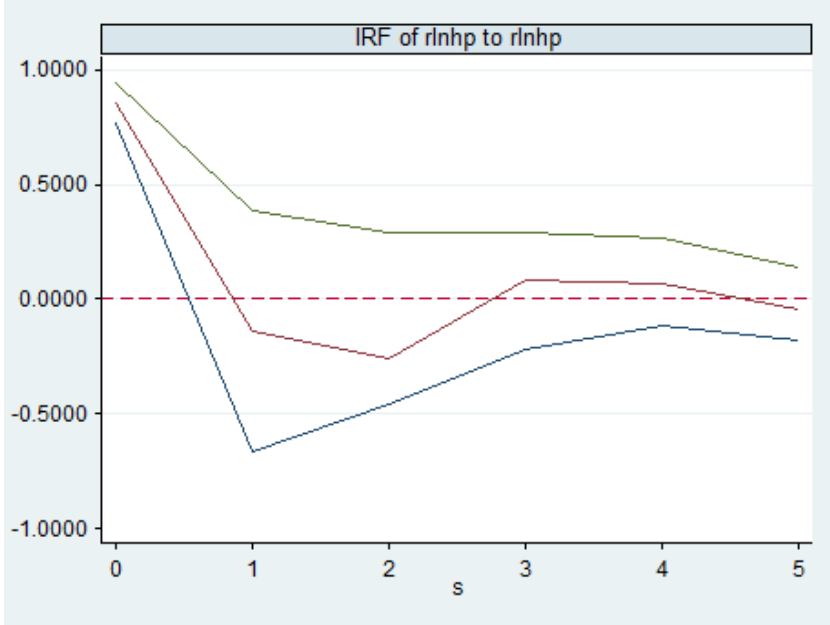

Fig. 1. Impulse response of real estate price change rate to real estate price change.

First, analyzing the change in the real estate equilibrium price impacted on the change of real estate prices. Judging from the direction of change, after the current period of a positive impact on the real estate equilibrium price, the change in the rate of change of Chinese real estate equilibrium price appears as a response of falling, then rising and then falling, and then positively and negatively then positively, Finally, a phenomenon of negative response. In terms of responsiveness, the highest value is $0.8 \%$ of the first period. From the response time point of view, the response time is basically to the third period.

From the above three aspects, under the positive impact of the real estate equilibrium price itself, the real estate price in the early stage is greatly influenced by the fluctuation of its own price, which may be due to the people's forecast of the real estate price and the increase of the real estate price to its own influence. After the first two years, the government intervened in the real estate price changes, the impact of the increase of real estate prices on real estate prices began to decrease. Finally, its effect gradually weakened.

Secondly, analyzing the change in land supply impacted on the change in real estate prices. From the change direction, the current supply of land to a positive impact, the changes in real estate prices, firstly negative to positive and negative after a response. From the perspective of response intensity, the highest level of change was $0.02 \%$ in the first period. From the response time, the duration is more than five periods.

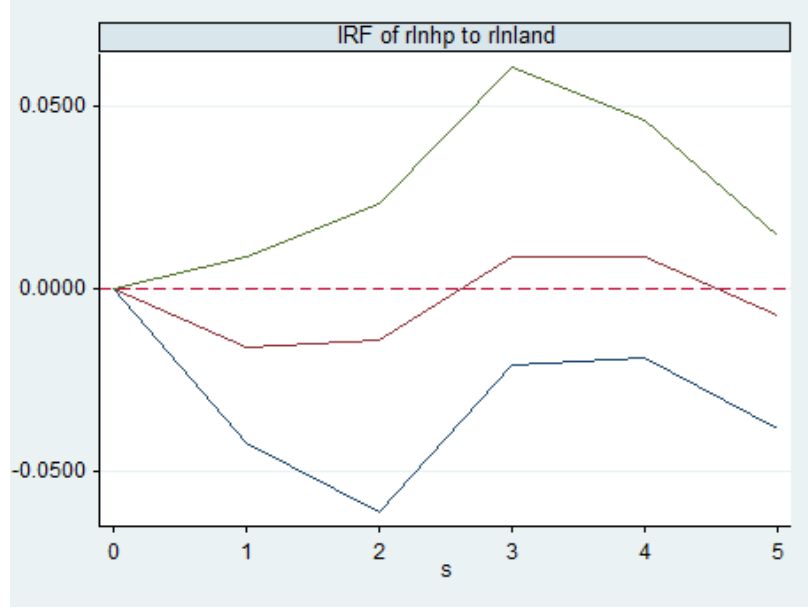

Fig. 2. Impulse response diagram of the rate of change of real estate prices to changes in land supply.

From the above three perspectives, under the impact of a positive change in land supply, the growth rate of real estate prices will slowly decline in the early period. In the second to third periods, the change in real estate prices will be affected by the supply of land. The smallest, and then in the fourth year when the real estate price changes affected by the impact of land supply increased, and finally in the fifth year of its effects have a downward trend. This is because the development of land into real estate takes a certain period of time, so the increase in land supply in the first two years has reduced the impact on real estate prices, and in the third year, the increase in land supply has turned into real estate supply. At this point, the impact of changes in land supply on real estate prices slowly strengthened. 


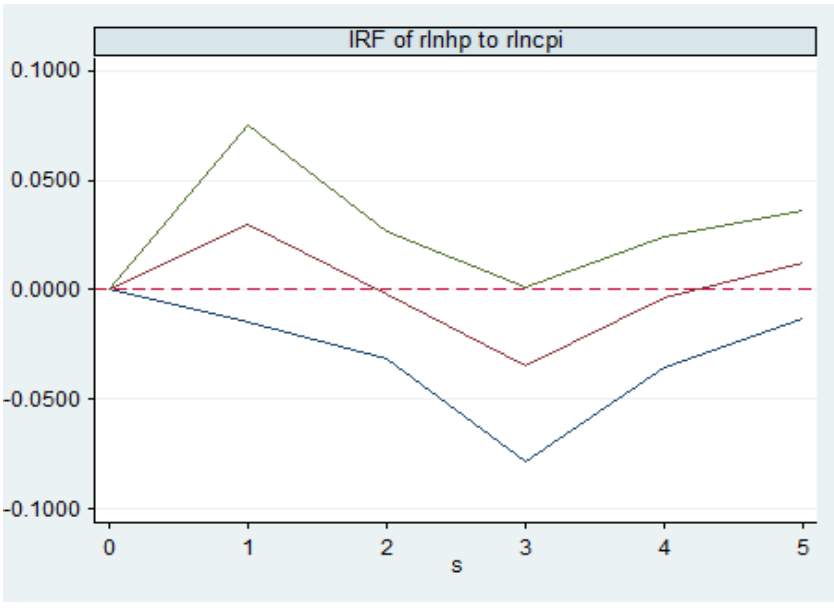

Fig. 3. Impulse Response Diagram of Rate of Change of Real Estate Prices to Changes in the inflation rate.

Thirdly, analyzing changes in inflation rate impacted on the rate of change of real estate prices. In terms of the direction of change, under the positive impact of the current inflation rate, the growth rate of the real estate price is going to be followed by the positive and negative response to the negative. From the strength of the response, the highest value of the change was $0.03 \%$ in the first and third periods. From the response time, the duration is more than five periods.

From the above three aspects, the positive changes in the inflation rate, and the impact of real estate prices two years ago are relatively large, and the impact of the back gradually becomes weakened. It is possible that the rise in the inflation rate leads to an increase in the construction materials for real estate, thus making real estate prices more likely to be affected by the inflation rate. For the government central bank can curb rising inflation and adopt the tighter monetary policy, the real estate prices by the impact of inflation have declined. So in the long run, the impact of inflation on real estate prices lower and lower.

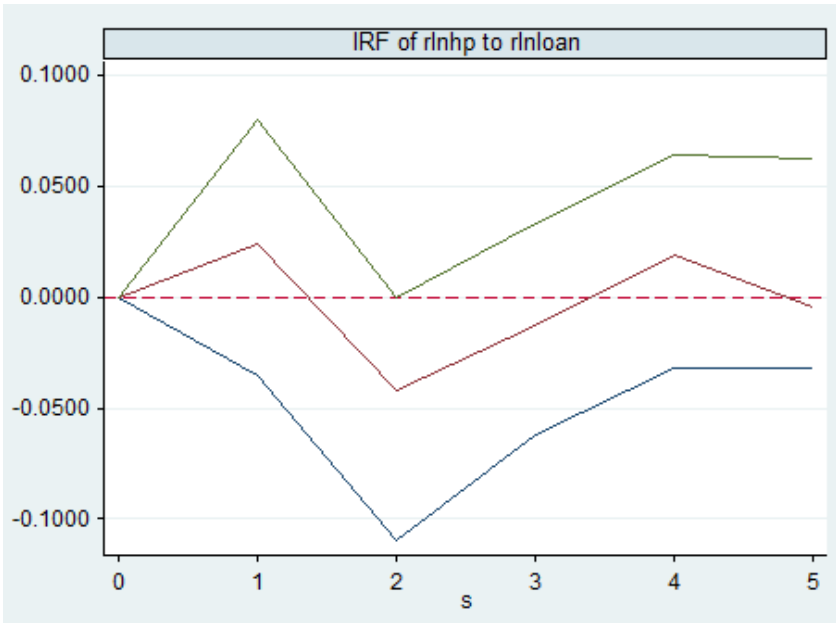

Fig. 4. The rate of change of real estate prices on real estate development loans changes in the impulse response diagram.
Fourth, analyzing the impact of changes in real estate development loan amount on the rate of change of real estate prices. From the perspective of change, under the positive impact of the current loan amount on real estate development, the growth rate of real estate prices shows a positive-negative and a negative-positive response, and the positive response is lower than the negative response. From the point of view of response intensity, the highest value of its change was $0.04 \%$ in the second period. From the time of response, it lasts for more than five periods.

From the above three aspects, real estate prices by the growth of real estate development loans increases, and then weakens at a larger margin, and its influence is slowly reduced. This may be making real estate developers have sufficient funds, due to the increase in real estate development loans in a year. So they do not have to rush to sell the house. As the sales price increases, the impact of this time is slowly increasing in the long term. The real estate development loans will increase when the amount of real estate supply will increase, helping to curb real estate prices, so the impact of the real estate development and investment at this time on the real estate prices is significantly weakened.

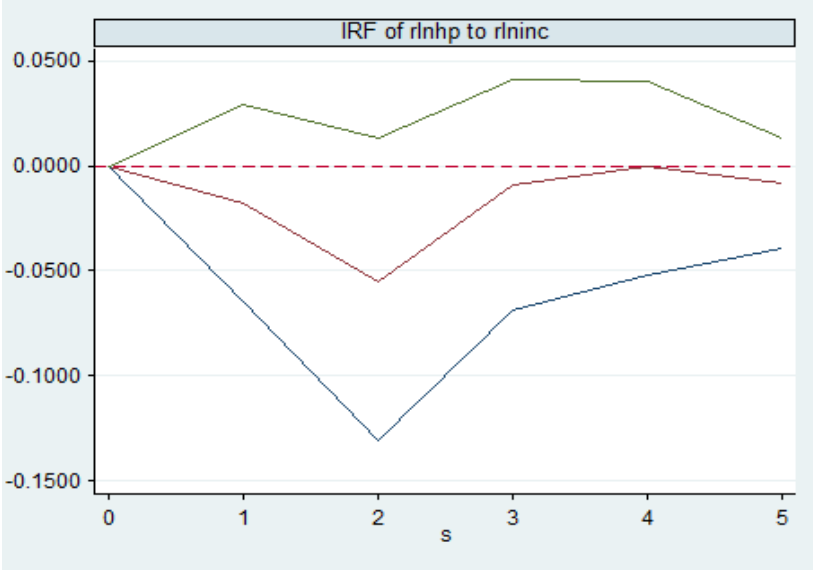

Fig. 5. Impulse responses of changes in real estate prices to changes in per capita income.

Fifth, analyzing the influence of the change of per capita disposable income of urban households on the rate of change of real estate prices. In light of the change direction, the performance of the growth rate of real estate prices has been negatively impacted by a positive impact on per capita disposable income of urban households in the current period. From the response strength, the highest response in the second phase is $0.05 \%$. From the response time point of view, the impact of time after the fifth period becomes weaker than previous period. From the response strength, the highest response in the second phase is $0.05 \%$. From the response time point of view, the impact of time after the fifth judging from the above three aspects, based on a positive impact on per capita disposable income of urban households, the change in real estate prices has been weakened over a period of five years, which shows that in the case of people getting rich. The increase in income does not mean that people will reinvest additional income into the real estate market, making the impact of income on real estate prices getting lower and lower. 


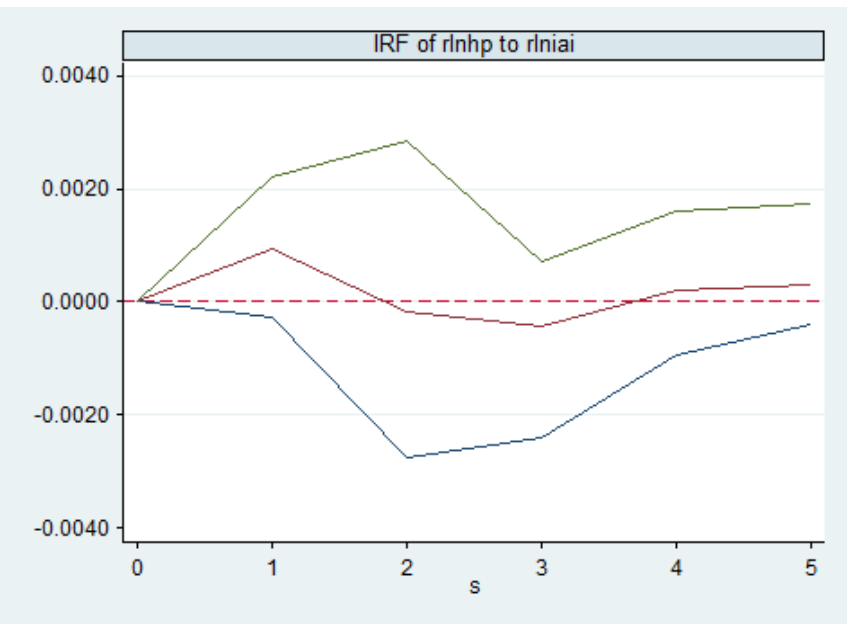

Fig. 6. Impulse response graph of the rate of change of real estate prices to changes in investment in social housing.

Sixthly, analyzing the impact of the changes in the investment of social security on the rate of change of real estate prices. Judging from the direction of change, under the impact of a positive investment in the amount of affordable housing in the current period, the growth rate of real estate prices will be positively followed by a negative and then positive response. In terms of response strength, the highest response value is $0.001 \%$ in the first phase. From the response time point of view, short-term impact, the long-term effect is relatively large.

From the above three perspectives, the effect of a positive change in the amount of investment in affordable housing on real estate prices has been increasing in the first two years, while the subsequent effects have been relatively weak. This may be due to the fact that the increase in the amount of this investment in the short term has affected the increase in construction costs. At this time, it has a direct impact on real estate prices, so its effect has been increasing. After two years, the completion of the security housing has increased the supply of housing and eased the rigid requirements of real estate. Therefore, the effect is reduced at this time, and even a negative effect will occur. Therefore, the price of real estate will decline accordingly. However, in the long run, insufficient investment in affordable housing will increase the price of affordable housing, which will affect the rise in real estate prices. Therefore, the degree of impact after five years will increase.

\section{POLICY IMPLICATION AND CONCLUSIONS}

\section{A. Policy Implication}

From the above study, it is difficult to intervene between the real estate prices itself and the income factor. As for the inflation rate factor, the increase will definitely cause the government to adopt a tightening monetary policy, which will lead to a drop in real estate prices. The effect of the long-term policy will also gradually weaken, eventually bringing the impact of inflation on real estate prices close to zero. Therefore, the following three factors should be proposed in the following three policy recommendations:

\section{1) Land Policy}

The rise in land prices has always affected the rise in real estate prices. According to the arrangement of Chinese first land finance system, local governments often strictly control land supply scales through the combination of "recruiting", "patching" and "hanging" methods, controlling in shortage of land supply and rising land prices. At the same time, rising land prices will lead to rising real estate development costs, which in turn will drive up real estate prices. Therefore, the government should expand the supply of land in order to curb the excessive increase in land prices caused by insufficient land supply. The system of restricting land development in the secondary market and implementing deadlines can be adopted to crack down on private capital and developers in their efforts to cut downland and copy land.

\section{2) The Amount of Real Estate Development Loan}

Its impact on real estate prices is a short-term increase, but it will reduce real estate prices in the long run. Therefore, the government can appropriately increase the amount of real estate development loans, but the increase in loan amount should not be excessive, and in order to prevent adverse effects, the impact in the short term must be within the scope of economic changes. Although house prices have risen in the short term, for the long-term, the increase in the amount of loans for real estate development has a good effect on the suppression of real estate prices. Therefore, the government needs to increase the amount of loans.

\section{3) Safeguard Housing Policy}

The impact of the construction of affordable housing on the real estate industry is also an important factor because the construction of affordable housing directly affects the rigid demand of the real estate industry and can fundamentally restrain the rise in real estate prices. However, there is also a need for certain plans for the construction of affordable housing to prevent intermittent investment in affordable housing. In addition, when the protection housing policy is implemented, the government needs to pay attention to the distribution of the security housing after the housing is built. The scientific allocation of affordable housing to avoid the problem of idleness in security housing allows this policy to achieve the best results.

\section{B. Conclusion}

This paper adopts the data of real estate prices, economic factors, and non-economic factors in 31 provinces and cities, and the panel VAR model to examine the explanatory power of relevant influencing factors by the panel VAR model impacted on the house prices.

Specifically, the author proposes recommendations as follow. Firstly, changes in real estate prices are significantly affected by prices themselves, inflation, and income. Among these three factors, within two years, the changes in real estate prices and changes in the inflation rate have a greater effect on real estate prices and the best effects within the first two periods. Two years later, the effects of these changes will slowly decrease. The impact of income on real estate in recent years has been reduced. Secondly, of the six factors studied in this paper, in addition to the impact of land supply and income, 
the impact of the other four factors on real estate price changes in the previous two years has been increasing, and most of them have been in the previous two years. Its effect has reached its maximum, and its effect has been gradually weakened after two years.

\section{ACKNOWLEDGMENT}

The author thanks Pro.Love for his Stata code and the editor and anonymous referee for their comments.

\section{REFERENCES}

[1] Li J.B., Empirical research on the relationship among residents' income, demographic structure, economic growth and real estate price. Hebei Corp ,2017,3: 46-7.
[2] Love I. and Zicchino L., Financial development and dynamic investment behavior: Evidence from panel VAR[J]. Quart Rev Econ Fin, 2006,46: 190- 210.

[3] Lu Q., On the relationship between real estate prices and macroeconomics. Rural Econ Technol, 2016,4: 48-9.

[4] Lu Y., Empirical study on the influence of regional industrial structure adjustment on the transmission mechanism of monetary policy: Based on panel VAR model. Exploration Problems Econ Issues, 2016,10: 10-7.

[5] Shi Y.P., Per capita income, monetary policy and real estate price: an empirical study on VAR. Credit Rating, 2015,9, 81-5.

[6] Sun T. and Zheng X.Y., Macroeconomic impact of dynamic changes in real estate prices in China: an empirical analysis based on FAVAR Model. J Guizhou Univ Fin Econ, 2015,5: 26-35.

[7] Wang Q.Y., Wang A.L. and Chang K.A., Analysis of the joint impact of regional real estate investment on economic basics. Contemp Econ, 2017,4: 16-9.

[8] Wu S.B. and Liu X.F., A study of the relationship between real estate prices and economic growth in China under the new normal state. Acad Forum, 2014,37: 69-72. 